\title{
Effect of yogic practices on Static \& Dynamic flexibility of College Student
}

\author{
Dr. Langpoklakpam Tamubi Devi ${ }^{1}$ Dr. Nongmaithem Sunderlal Singh ${ }^{2}$ \\ ${ }^{I}$ Research Scholar in Physical Education, Manipur University, India. \\ 2 Assistant professor, faculty of Physical Education, D.M. College of Commerce, Imphal, Manipur.
}

\begin{abstract}
To see the effect of six weeks yogic exercise in college students 38 BPE $1^{\text {st }}$ year students of IDCPE Ishwar Deshmukh Collge of Physical Education Nagpur were selected as a subject. The pre-test and post test had been taken by using Dynamic flexibility test, side split flexibility test and shoulder and wrist elevation flexibility test tools. To determine the difference between the 2 groups (initial and post test) of one group experimental group of the BPE $1^{\text {st }}$ year student t test was employed at 0.05 significance level. And to determine the training effect the t test for comparison mean was employed for two tails at the confidence level 0.05 level of significant.

The comparative between the initial and post test of dynamic flexibility test, side split flexibility test and shoulder and wrist elevation flexibility test for the state level football players were found to be statistically no significant at 05 confidence level.
\end{abstract}

Key wards: Dynamic flexibility, Side sliding flexibility, shoulder and wrist elevation, BPE, IDCPE, comparative t test.

\section{Introduction}

Generally speaking the average person's level o consciousness is fairly low. He is enslaved to life and lives on false hopes and illusions. Here are many reasons why Manipuri's are so fond of games and sports since time immemorial. He spends his life in ignorance, experiencing joy and sorrow, success and failure, love and grief without ever really coming to the ultimate realization. The great mass of humanity allows itself to be led and dominated by the sense. Under the influence of sensation, people commit errors, which they subsequently regret. They delude themselves by looking for peace, happiness and self-accomplishment through the pleasures of the sense. It is quite normal for the human mind to want to discover the undertaking facts and principles of nature by means of a physical experience. We notice that the experience we have on a physical level are only temporary, superficial and some time illusory, since our senses are limited.

Perfection of personality - Mukti, Moksha \& Jivanmukti. The problem of perfection of personality naturally leads one to undertake the study of different methodize efforts toward self perfection. Yoga is one of the most effective methods, by which the perfection of the latent potentialities, partially expressed in man is attained. Perfection is not an addition - addition of capacities or a it is the manifestation of those potentialities which are inherent in man and which lie idol until and efforts is made to bring them to the surface. Jnana, Bhakti, Karma and Raja are the several means to attain the perfection of personality. Flexibility can also be called freedom to move, the capacity of a joint to move fluidly through its full range of motion, the ability of a person to move a part or parts of the body in a wide range of purposeful movements at the required speed. It is the ability to move a joint through a normal range of motion without unduestress to the musculo tendinous unit. Flexibility has important interrelationship with other performance factors. Joint structure plays important role in flexibility for, ex-shoulder joint $\&$ hip joint due to ball \& socket joint move in many directions, with a greater range of motion. If flexibility is up to the mart greater range of movement enables the muscles to develop more force \& speed. It has energy saving effect. Good flexibility therefore helps in achieving higher movement economy. The motor learning requires adequate level of flexibility of the concern joints. Inadequate flexibility always leads to errors in movement execution. Flexibility helps in absorbing the shock and external forces tending to cause an injury. But flexibility helps to prevent injuries only if it is optimum. Flexibility is of two types passive and active. Passive flexibility is the ability to perform movement with greater range with external help, for example - stretching with partner. Active flexibility is nothing but a ability to do movement with greater scope without anybodies help. For example - stretching without partner.

Active flexibility is also of two types - static and dynamic. Static flexibility is required for movement done while individual is in the static state i.e. standing, sitting or lying. Dynamic flexibility is required for executing movement with greater range when individual is moving. Active flexibility is always less than the passive flexibility. The dynamic flexibility is always less than static flexibility and is heavily dependent on the motor coordination. The terms general \& specific flexibility are also commonly used to denote the levels of flexibility of all the important joints of the body specifically shoulder, hip \& trunk. Where as special flexibility 
is the ability to do movements of a sport with greater range. As stated earlier flexibility is largely depend upon anatomical structure of the joint. The manner in which the bone ends are joined each other basically decides the type of movements possible in the joint. Greater mobility is in ball and socket joint. The elasticity of ligaments can be increased up to some extent by training, but length of the ligaments can't be change by training. The ligaments give stability to joint. If the length of ligaments increase ligaments remains in stretched state it lower the stability of the joint. Stretchability of the muscle also affects range of movements. The muscle if to regularly stretch tends to get shorter there by restricting the range of movement possible of joint. Stretchability of muscle can be increase by training. Dynamic flexibility is largely depend coordinative ability. Balance between agonists $\&$ antagonists muscles is important. Strength is also necessary for degree of flexibility. For range of movement minimum level of strength is essential in antagonist muscles. Flexibility therefore is a very sensitive motor activity factors like a day temperature, muscle temperature, time of the day, emotion, massage, warming up also affect the flexibility. For improvement and development of flexibility starching exercises are used. Methods of doing stretching exercises are as follows: -

1. Ballistic method - This is the oldest method of stretching. In this method joint is stretched rhythmically to its maximum range, with swing movement, ballistic means swing movement. This method is very effective but having risk of injuries, due to over stretching sometime. This method is most effective for developing dynamic flexibility.

2. Slow stretch and hold method - In this method is stretched to the maximum limit with slow rate. For best results the joints must be held in the static state for maximum 3-8 seconds. This method is very effective for improving passive flexibility.

3. Post iso metric stretch method - In this method a muscle is first contracted iso-metrically for 6-7 sec. The isometric contraction should be maximal. After this muscle is gradually stretched to its maximum limit and is held in the position for 8-10 sec. this procedures is to be repeated 4-8 times for each muscle group.

Greenwhich and O Nail found gradual declines in the flexibility from age 6 to 12 and then increase through age 18. Hupprich and Sigerseth in their investigation of group of girls 9 to 15 years of age reported that there was a trend towards decreasing shoulder, knee and hip flexion from ages 12 through 15 . Flexibility can be developed at any age given the appropriate training, however, the rate of improvement will not be the same at every age, nor will the potential for improvement.

Asanas - Means and measure of flexibility: - The asanas Yogic postures have a long history. According to ancient Hindu tradition, God shiva is said to have demonstrated 8,400,000 asanas - as many as there are living species to enable man to keep his body in perfect health so that he could attain highest level of his spiritual development. In Shiva Samhita 84 postures have been mention while in second upadesh 32 postures are described. In fact near about 20-25 asanas practiced are required to maintain \& reestablish perfect health. Asanas along with pranayam, Bandha, Mudra are very good for health. Not only they give exercise to external also provides unique exercises to the internal organs. Yoga stretching and relaxation are beneficial to the sports man. The concept of yoga stretching has already been widely accepted by the western world. Yoga stretching contributes to gain flexibility, which increase quickness, jumping ability and suppleness. Another benefit from yoga stretching is it helps the muscles to get back to the relaxed condition within minute after a vigorous competition.

Statement of problem: The problem is stated as follows, "Effect of yogic practices on static \& Dynamic flexibility of college Students."

Objective of the Study: objective of this study was stated as follows -

1. To find the effect of yogic practices on flexibility.

2. To find out the comparative picture of effect of yogic practice on static \& dynamic flexibility.

3. To find the effect yogic practices on ball and socket \& trunk joint.

\section{Methodology:}

Selection of Subject - this study was carried out on the students of Ishwar Deshmukh Collge of Physical Education Nagpur. Student of BPE $1^{\text {st }}$ year class were selected for this study. Previously it was decided to conduct the experiment on 20 students. This year 38 students have taken admission for BPE $1^{\text {st }}$ year class. When researcher elaborated and informed them about this project and selection procedure of the students all were keen to take part actively. BPE $1^{\text {st }}$ year students being fresher in the field of physical education have lot of enthusiasm about the various activities of physical education. To acknowledge there enthusiasm and activeness researcher, instead of selecting the students, decided to take all students, 38 in all, as a subject for this investigation. Out of 38 students 5 were girls students and 33 were boys. Their average age was 20 years ranging from 18 to 26 years. This sample is heterogeneous as far as cultural \& professional background is concerned. These students are from different state like H.P, M.S, Gujarat, Orissa, Jharkhand, MP, J \& K etc. Two students are foreign from 
Maurisas. Most of the students play different games \& participated in different tournaments. All students were willing to take active part in the project and also assured to maintain regularity, health and discipline in the class.

Experimental Design - The single group design was applied for this study because purpose of this study was to determine the effect of one experimental factor from a particular situation.

Test of flexibility - The purpose of this investigation was to examine the effect of yogic practices on the flexibility. The investigator also decided to see the effect of yogic practices on both the types of flexibility i.e. static \& dynamic. To delimit the scope of the problem investigator examined the effect of yogic practices on few major joints i.e. shoulder, hip \& trunk. Following test were selected and administrated to judge the degree of flexibility. 1. Side Splits test. 2. Shoulder and wrist elevation test. 3. Dynamic flexibility test, were selected as tools to collect the data to judge the degree of flexibility.

\section{Admission of test -}

Initial test - all the 38 students of BPE $1^{\text {st }}$ year class who were selected as a subjects were given three flexibility tests given below -

1. Side Splits test.

2. Shoulder and wrist elevation test.

3. Dynamic flexibility test

Were selected \& administered to judge the flexibility of the students. To see the effect of yogic practices on flexibility twelve asanas including shavasanas were selected for the yogic training programme. as the students were fresher in the field of physical education, they were not acquainted with the knowledge and techniques of asanas. Hence researcher conducted one week basic education programme of asanas for the students. Prior to administration of test they were given demonstration \& information about flexibility test. They were also allowed to take trial if they desire. They were given 10-15 minute times for personal warm up.

Final test - After completion of 6 weeks yogic practice programme post test (final test) was conducted on flexibility both static \& Dynamic as mentioned in initial test. To determine the difference between the 2 groups (initial and post test) to determine the training effect the $t$ test for comparison mean was employed for two tails at the confidence level 0.05 level of significant.

III. Result:

Table no.1 Side split test of flexibility score

\begin{tabular}{|l|l|l|l|l|}
\hline \multirow{2}{*}{ Level } & \multicolumn{2}{|l|}{ Initial test score of students } & \multicolumn{2}{l|}{ Final test score of students } \\
\cline { 2 - 5 } & Boys & Girls & Boys & Girls \\
\hline Advance (3-0) Boys & 1 & - & 1 & - \\
\hline Advance intermediate (8-3 1/4) & 1 & 1 & 1 & 1 \\
\hline Intermediate (17 1/2 - 8 1/4) & 29 & 4 & 30 & 4 \\
\hline Advance Beginner (22 1/2-17 3/4) & 1 & - & 1 & - \\
\hline Beginner (Above - 22 3/4) & 1 & - & - & - \\
\hline Total & 33 & 05 & 33 & 05 \\
\hline
\end{tabular}

Note: - classification of girl students was done as per their norms.

The above table indicates the initial and final test score of side split test of flexibility. Out of 33 boys 29 could score intermediate level score and in rest of the categories one student each. Out of 5 girls students 4 scored intermediate level score and one advanced intermediate level score. It shows that in both boys and girls maximum students are of intermediate level in side split test of flexibility. After 6 weeks of yogic practice training when the final test was conducted out of 33 boys students 30 scored intermediate level where as out of five girls 4 girls students scored intermediate level rank. It shows that there is no much more improvement in the side splits test score of flexibility after 6 weeks yogic training programme.

Table no. 2 ' $t$ ' test for side splits test of flexibility

*not significant

\begin{tabular}{|l|l|l|l|}
\hline Test & Mean & SD & ' $t$ ' \\
\hline Initial test & 12.37 & 8.63 & $0.19^{*}$ \\
\hline Final test & 11.97 & 9.64 & \\
\hline
\end{tabular}

Table no. 2 indicates the mean difference is 0.40 with ' $t$ ' value 0.19 which is not statically significant. it shows that there is no immediate effect of yogic practice on flexibility in general and hip joint in particular, but the trend of improvement is there. 
Table no.3 Shoulder and wrist elevation test

\begin{tabular}{|l|l|l|l|l|}
\hline \multirow{2}{*}{ Level } & Initial test score of students & \multicolumn{2}{l|}{ Final test score of students } \\
\cline { 2 - 5 } & Boys & Girls & Boys & Girls \\
\hline Advance (6-0) Boys & - & - & - & - \\
\hline Advance intermediate $(81 / 2-61 / 4)$ & - & - & - & - \\
\hline Intermediate $(11 / 2-81 / 2)$ & - & - & - & - \\
\hline Advance Beginner $(121 / 2-11 / 4)$ & 1 & - & 3 & - \\
\hline Beginner (Above $\left.-12 \frac{1}{4}\right)$ & 32 & 05 & 30 & 05 \\
\hline Total & 33 & 05 & 33 & 05 \\
\hline
\end{tabular}

Note: - Girls classification as per their norms.

In above table indicates the score of shoulder \& wrist elevation test of flexibility. In the initial test out of 33, 32 boys obtained beginners level score and only one could score advanced beginner rank points. Where as in girls sections all girls students scored beginners level points. After 6 weeks yogic practice programme only 2 boys students scored higher grade and elevated from beginner to advanced beginners. In girls section there is no change in the performance.

Table no. 4 ' $t$ ' test for shoulder and wrist elevation test

*not significant

\begin{tabular}{|l|l|l|l|}
\hline Test & Mean & SD & ' $\mathrm{t}$ ' \\
\hline Initial test & 17.11 & 8.45 & $0.56^{*}$ \\
\hline Final test & 16.16 & 6.22 & \\
\hline
\end{tabular}

Table no. 4 indicates mean, SD and ' $t$ ' of initial and final test shoulder and wrist elevation test of flexibility. The mean difference is 0.95 with. The SD of initial and final test is 8.45 and 6.22 respectively. ' $t$ ' is 0.56 which is not statically significant. This results does not confirm the immediate effect of yogic practice on flexibility as ' $t$ ' value is not statistically significant.

Table no. 5 ' $t$ ' test for dynamic flexibility test

*not significant

\begin{tabular}{|l|l|l|l|}
\hline Test & Mean & SD & ' $\mathrm{t}$ ' \\
\hline Initial test & 7.11 & 1.35 & \multirow{2}{*}{$1.67^{*}$} \\
\hline Final test & 7.16 & 1.21 & \\
\hline
\end{tabular}

The result presented in table no. 5 reveled little bit improvement in the dynamic flexibility after 6 weeks of yogic practice programme. The mean difference is 0.05 and ' $t$ ' value is 1.67 which is not statically significant. Through improvement may not be statically significant but it can be said that yogic practices helps to improve to dynamic flexibility.

\section{Discussion:}

The purpose of this investigation was to see the effect of yogic practices on flexibility. As stated in detail description of analysis the data it is observed that there is no immediate effect of yogic practices on flexibility. But the yogic practices help to improve dynamic flexibility and also the other joint flexibility as trend showed in table no, $1 \& 2$.

\section{References:}

[1]. Sri Ananda, "The complete Book of yoga, Harmony of body and Mind," Orient Paperback New Delhi, - Page - 7.

[2]. Sudarshan kumar Birla, "Yoga for better living and self realization," Kalyani Publication, Ludhiana, 1999 page- 10

[3]. Nigam Braj Bihari, "Yoga power - The path of personal achievement," Dominated Publication \& Distribution, New Delhi - 02 page 3 to 5 .

[4]. Alter M.J., "Science of Flexibility", Human Kinetics, 1999, page 3 \& 4

[5]. Hardayal Singh, "Science of sports training," DVS Publication, New Delhi, 1995, page-157

[6]. Kansal D.K., "Test \& Measurement in Sports \& Physical Education,” D.V.S. Publication New Delhi, First Edition 1996, page-192

[7]. Swami Kwalayanada, "Scientific survey of the yogic poses", S MYM Samiti Lonavala 1999 page 2.

[8]. Amit Gupta, jaspal Singh, Sandhu and shyamal koley "A study on the physical Fitness spinal mobility and flexibility.

[9]. Vibha Bhola 'relationship of absolute Leg Length, relative Leg Length, Foot Lentgh, Dynamic power, Ankle Flexibility and agility of jumping Ability to volleyball using three strides Rhythm".

[10]. Peter singerseth and C. Chester Haliski; The flexibility of of football players "Research Quarterly Vol 21 No. 1 (December 1950). PP. 394-398. 